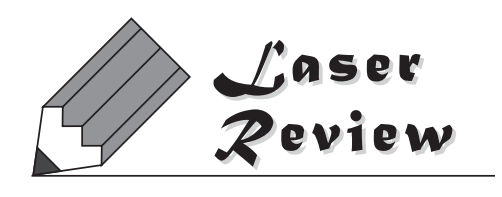

\title{
高機能回折光学素子による先端レーザー技術
}

\author{
尾松 孝茂 \\ 千葉大学大学院 融合科学研究科 (厂 $263-8522$ 千葉市稲毛区弥生町1-33)
}

\section{Advanced Laser Technologies Based on A Functional Diffractive Optics}

Takashige OMATSU

Graduate School of Advanced Integration Science, Chiba University, 1-33 Yayoi-cho, Inage-ku, Chiba 263-8522

(Received June 30, 2009)

\begin{abstract}
Functional diffractive optics including a volume Bragg grating, a polarization selective mirror, as well as photorefractive nonlinear materials has potentially been applied to explore advanced laser technologies such as coherent beam coupling, radially-polarized beam generation, and high-power laser outputs with high beam quality. In this paper, we address several successful demonstrations of advanced lasers by utilizing the functional diffractive optical elements.
\end{abstract}

Key Words: Laser, Diffractive optics, Nonlinear optics

1. はじめに

レーザーを応用する分野が拡大するに伴い, レーザー の光波としての性質(周波数・振幅・位相・波面・パル ス波形など)を自在に制御してレーザー光波を目的に合 わせてカスタマイズする, いわば, 光波のシンセサイジ ング(光波シンセシス)が重要になってきた，光波シンセ シスにとって回折光学素子は光波の位相や電場ベクトル の時間・空間分布を制御する重要な光学素子である.

回折光学素子は, ここ数年で大きく進化した，体積型 ホログラフィック回折格子 ${ }^{1,2)}$ や偏光選択性回折格子 ${ }^{3,4)}$ に代表される高機能回折光学素子は高出力レーザーのス ペクトル狭帯域化, 通常の共振器では固有モードとして 発振しない軸対称偏光モードの発生, など高度な光波シ ンセシスを可能にする。 また，フォトリフラクティブ材 料 ${ }^{5)}$ や誘導ブリユアン散乱 ${ }^{6}$ に代表される動的ホログラ ム素子は超短パルスレーザーの波面制御，パルス波形制 御の多彩な光波シンセシスを可能にする.

本稿では, 光波シンセシスにおける回折光学素子の果 たす役割と最近の研究動向を回折格子の種類別に整理し て概説したい.

\section{2. 高機能回折光学素子}

2.1 体積型ホログラフィック回折格子(Volume Bragg Grating, VBG)

フロリダ中央大学CREOLのGlebovらのグループは phototthermorefractive (PTR) ガラスと呼ばれるNa, Zn,
Al-Silica系ガラスに紫外光を用いて体積型ホログラムを 記録し，熱定着する技術を研究してきた。このPTRガラ スに記録された体積型ホログラフィック回折格子 (Volume Bragg Grating, VBG) は, CW光に対して $100 \mathrm{~kW} / \mathrm{cm}^{2}$, $1 \mathrm{~ns}$ パルス光に対して $20 \mathrm{~J} / \mathrm{cm}^{2}$ という高い損傷しきい值 と $90 \%$ 近い高い回折効率を示す.

これまでに高出力半導体レーザー, チタンサファイア レーザー, Cr:LiSAFレーザーなどの広帯域レーザーの発 振スペクトル狭窄化 ${ }^{7,8)}$, 独立した複数の半導体レー ザーのコヒーレント結合9), チャープパルス増幅器にお けるパルス圧縮 ${ }^{10)}$ など，VBGを用いた様々な応用が実証 されている。 さらには，Ndイオンなどのレーザー活性 イオンを添加したPTRガラス ${ }^{11)}$ 開発されており, PTR ガラス素子ワンチップで小型で単一モード発振するレー ザーが実現できる可能性もある。

PTRガラスを用いたVBGによる高出力半導体レーザー の発振スペクトル狭窄化とアルカリ金属蒸気レーザー励 起 ${ }^{12,13)}$ に関する報告は本特集号における鄭らの解説記事 に譲り,ここでは, Venusらによる独立した2台の半導体 レーザーをコヒーレント結合した実験例を取り上げる9. 実験配置概念図をFig. 1に示す. $980 \mathrm{~nm}$ 帯半導体レー ザー (出力 $50 \mathrm{~mW}$ ) の外部に外部共振器ミラー用のVBG を配置してフィードバック光を戻し，狭帯域レーザー発 振 ( $<30 \mathrm{pm})$ させる. その発振光の一部をコヒーレント 結合用のVBGで回折し, 別の半導体レーザーに注入す る。その結果, 2台の独立した半導体レーザーが完全に 互いに同期する。同期後は外部共振器ミラー用のVBG を取り除いても2台の半導体レーザーの同期は持続する 


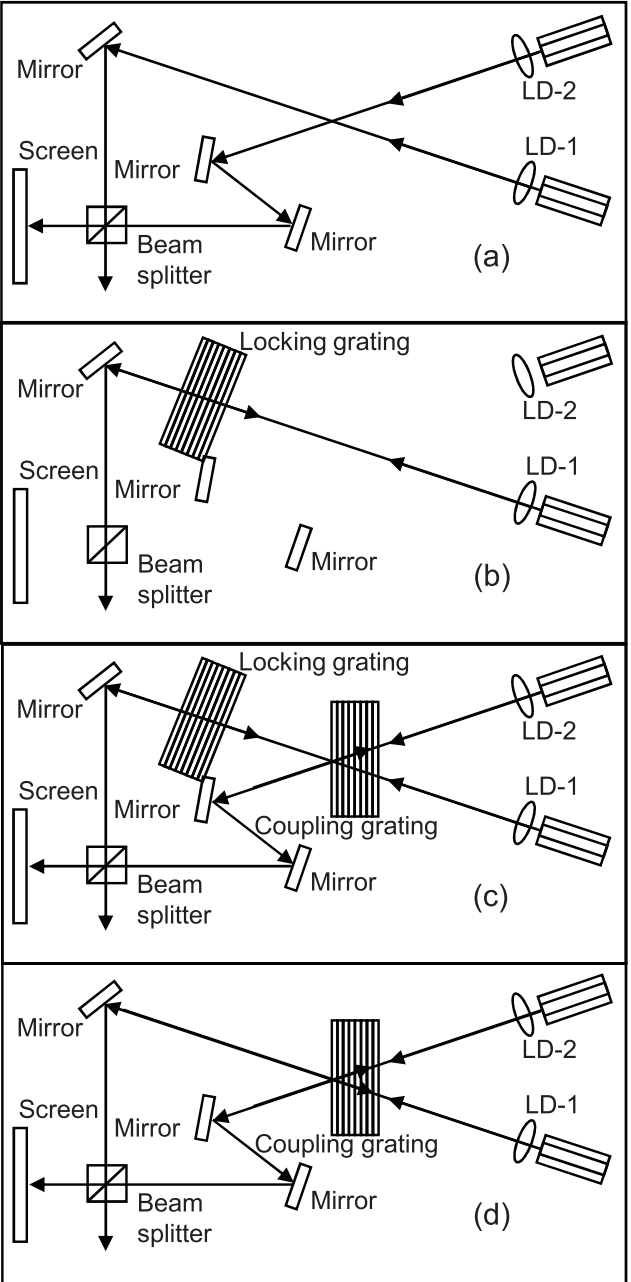

Fig. 1 Scheme diagram of coherent coupling of laser diodes. (a) Combining independent diodes;(b) spectral locking LD-1 by an external volume Bragg grating(VBG);(c) phase locking two diodes by another volume Bragg grating;(d) after the locking grating is removed.

(Fig. 2)。この実験で使用したVBGの回折効率は $98 \%$, 波長選択性は $100 \mathrm{pm}$ であった。最終的な実験光学系は 独立する2台の半導体レーザーの外部にコヒーレント結 合用のVBGを配置するだけの簡単な光学系であるため, 多数の独立な半導体レーザーをコヒーレントに結合する ことも難しくない．すでに同グループでは計算機シミュ レーション結果を報告している(14).

\section{2 偏光選択性回折素子}

偏光選択性回折素子の中でも, フォトニックラティス 社で開発した自己クローニング法によるフォトニック結 晶型偏光選択回折素子 ${ }^{15}$ は高い偏光消光比と設計自由度 を示す，これまでに, 径方向, 周方向の軸対称偏光子, 軸対称偏光モード用レーザー共振器ミラー, 軸対称偏光 変換素子などが開発されている。これらの素子を用いた 様々なレーザー16-18)が提案されているが，その中から， われわれが開発した高出力軸対称偏光モードレーザーを 取り上げ紹介する ${ }^{19}$.

レーザー装置の構成は, 側面励起型 $\mathrm{Nd}^{-} \mathrm{YVO}_{4}$ スラブ レーザー増幅器，1/4波長板，テレスコープ，全反射ミ

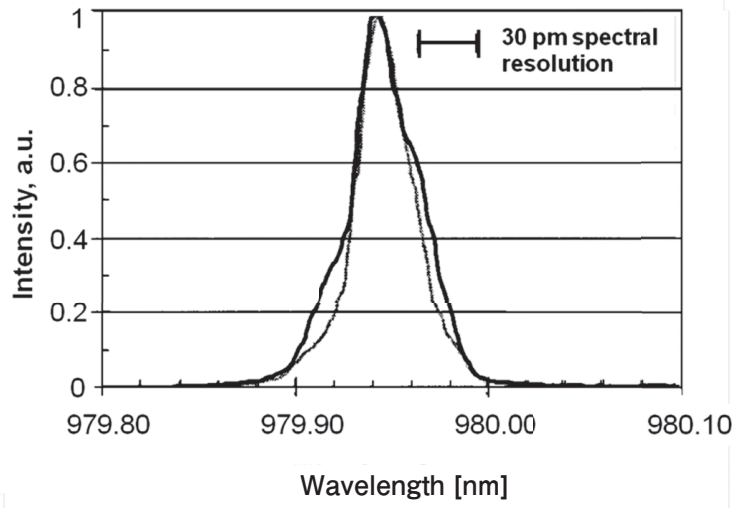

Fig. 2 Dark curve shows the lasing spectrum of LD-1 locked by a locking grating; Light curve shows the lasing spectrum of LD-2 locked by a coupling grating.

ラー, フォトニック結晶型偏光選択回折ミラーからなる (Fig. 3). 使用したNd: $\mathrm{YVO}_{4}$ スラブ結晶の方位は $a$-cut, 結晶サイズは $20 \mathrm{~mm} \times 5 \mathrm{~mm} \times 2 \mathrm{~mm}, \mathrm{Nd}$ イオン濃度は 1 at.\%であった. $\mathrm{Nd}: \mathrm{YVO}_{4}$ 結晶は強い偏光異方性を有す るので, 発振光の偏光は $c$-軸に沿った直線偏光にな る. 1/4波長板を用いて円偏光に変換し, 円偏光に対し て周方向偏光モードだけを選択的に反射するフォトニッ ク結晶型偏光選択回折ミラーで径方向偏光モードを出力 する.フォトニック結晶型偏光選択回折ミラーで反射さ れた周方向偏光モードはNd: $\mathrm{YVO}_{4}$ の強い誘導放出を受け て, 共振器を往復するうちに再び直線偏光になり，1/4 波長板に戻る。このような一連の偏光ダイナミクスを繰 り返しフォトニック結晶型偏光選択回折出力ミラーから は常に径方向偏光したレーザーだけが出力として取り出 される (Fig. 4)。共振器内部のテレスコープは発振する レーザーモードサイズを拡大し，フォトニック結晶型偏 光選択回折ミラーの開口を有効利用するために配置され ている. 出力ミラーの反射率が最適化されていないの で, 径方向モードの取り出し効率は $15 \%$ と高くないが,

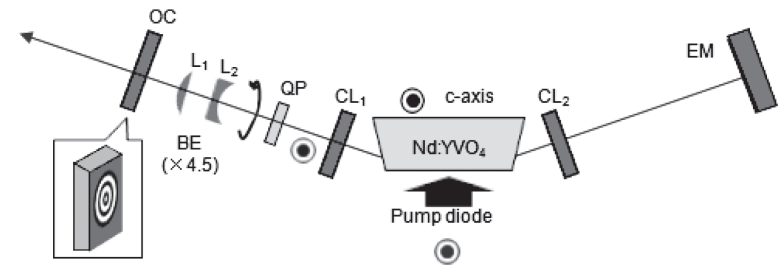

Fig. 3 Schematic diagram of radially polarized laser based on a $\mathrm{Nd}: \mathrm{YVO}_{4}$ bounce laser.

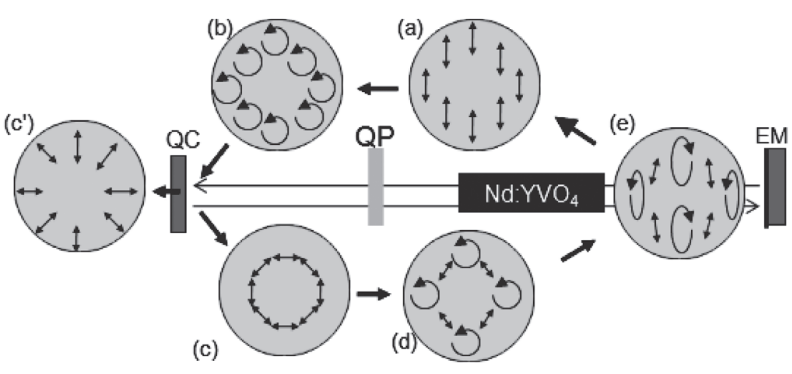

Fig. 4 Polarization dynamics of the laser mode in the laser cavity. 

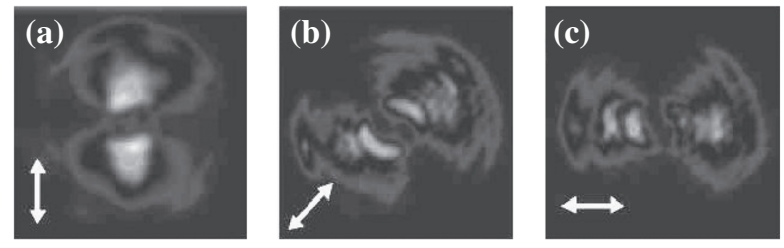

Fig. 5 Spatial forms of the radially-polarized output. Intensity profiles of (a) vertically-polarized component, (b) $45^{\circ}$-polarized component, and(c) horizontally-polarized component, respectively.

$6 \mathrm{~W}$ 以上の径偏光モードがレーザー出力として取り出さ れた(Fig. 5)。レーザー出力鏡をフォトニック結晶型偏 光選択性回折素子に変更するだけの簡単な光学系なの で,さらなるパワースケーリングやQスイッチパルス動 作やモードロック動作などへも展開できる.

\section{3 フォトリフラクティブ動的ホログラム素子}

最も広く利用されているフォトリフラクティブ材料は チタン酸バリウム結晶 $\left(\mathrm{BaTiO}_{3}\right)^{20,21}$ である. $\mathrm{BaTiO}_{3}$ 結晶 は可視から近赤外に至る広い波長感度と $10 \mathrm{~cm}^{-1}$ を超え る大きな二光波混合利得を示す。したがって, $\mathrm{BaTiO}_{3}$ 結 晶内部に記録された動的ホログラム格子を介して位相共 役波発生や光増幅が簡単に実現できる。 $\mathrm{BaTiO}_{3}$ 結晶の最 も重要な機能の一つである位相共役波発生は, レーザー の波面補償やスペクトル制御に応用できる。これまでに レーザーシステムの一部に $\mathrm{BaTiO}_{3}$ 結晶からなる位相共役 鏡を配置した発振器 一増幅器システム (位相共役発振器 一増幅器システム, Phase conjugate master-oscillator power amplifier, PC-MOPA)が数多く報告されている22-26). す でに回折限界に近いビーム品質で $25 \mathrm{~W} を$ ザー出力を達成した実験例も報告されているが，その詳 細については本特集号の縄田らによる解説記事に譲り, ここでは，ユニークな2つの実験報告例を取り上げる.

Godardらは, 回折格子とInGaAs系半導体レーザー $(1.55 \mu \mathrm{m})$ からなる外部共振器の間にフォトリフラク ティブ結晶であるCdTe結晶を配置したレーザーシステ 厶を提案した ${ }^{27,28}$. 実験配置図をFig. 6に示す。外部共振 器内で対向するモードがCdTe結晶に反射型フォトリフ ラクティブ動的ホログラム格子を記録する。このホログ ラム格子が体積型ホログラムとして機能して, 外部共振 器モードの同調を自動的に行う。この結果, 縦シングル

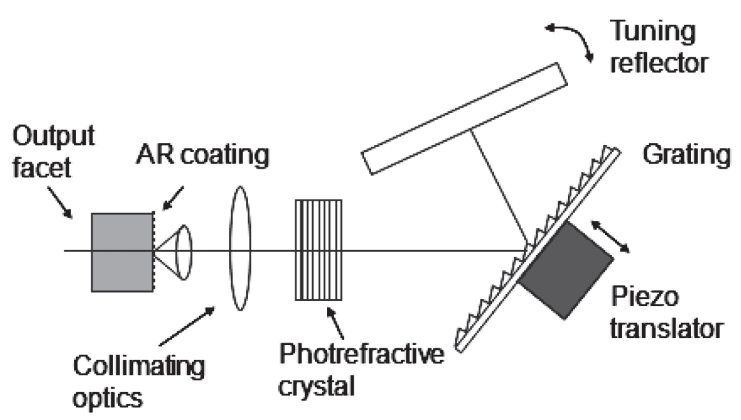

Fig. 6 Self-organized laser diode with an intra-cavity photorefractive volume Bragg grating.

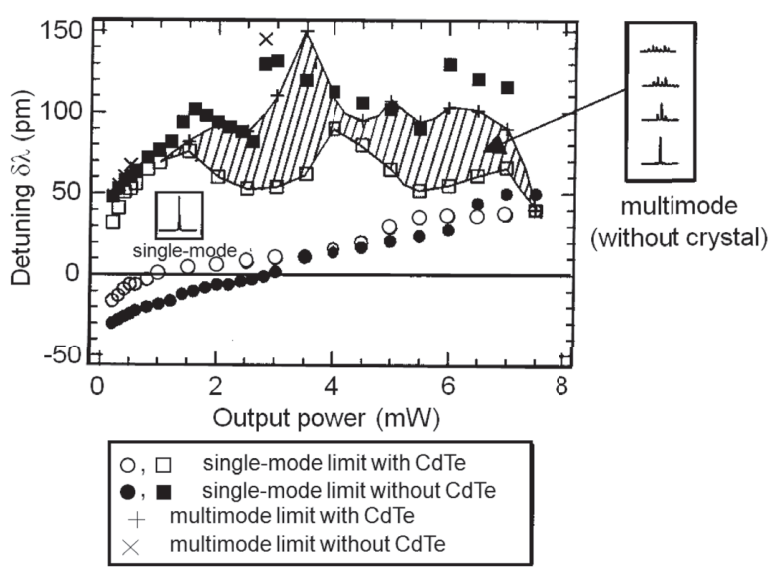

Fig. 7 Accessible range of $\delta \lambda$ under stable single-mode operation as a function of optical power at $1.6 \mu \mathrm{m}$ with and without a CdTe crystal.

モード発振可能な範囲が格段に広がる(Fig. 7)。この実 験はフォトリフラクティブ動的ホログラム格子を一種の VBGとして用いたもので興味深い.

また，側面励起Nd: $\mathrm{YVO}_{4} レ$ レ゙ー共振器の全反射ミ ラーの代わりに位相共役鏡を配置した位相共役レーザー 共振器が千葉大学とインペリアルカレッジから提案され ている ${ }^{29)}$ (Fig. 8)。共振器内部のフーリエ面近くに配置 された空間フィルターを時間反転波である位相共役波は 損失なく高効率に通過できるので，回折限界近いビーム 品質の空間モードを高効率にアライメントフリーで発振 できる. 励起パワー $22 \mathrm{~W} に$ 対して7.5 Wの連続波レー ザー出力を達成している(Fig. 9).

さて, 強誘電体中のキャリア移動を伴うフォトリフラ クティブ結晶の応答速度は比較的遅く，いずれの応用研 究でも $\mathrm{BaTiO}_{3}$ 結晶の遅い応答速度と如何にうまく付き合

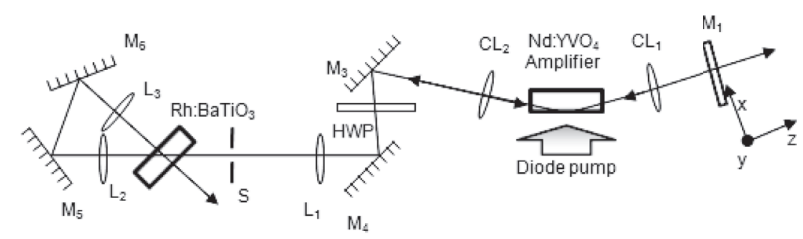

Fig. 8 Phase conjugate laser based on a Nd: $\mathrm{YVO}_{4}$ bounce laser in combination with a photorefractive phase conjugate mirror.

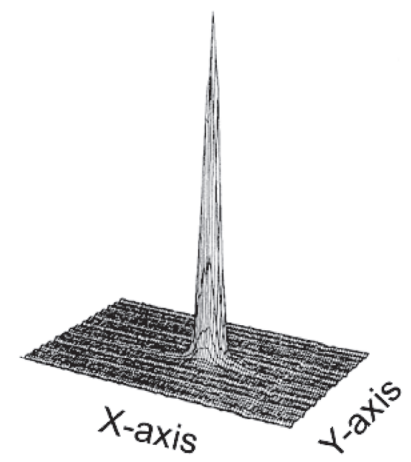

Fig. 9 Spatial form of the output from the phase conjugate resonator. 


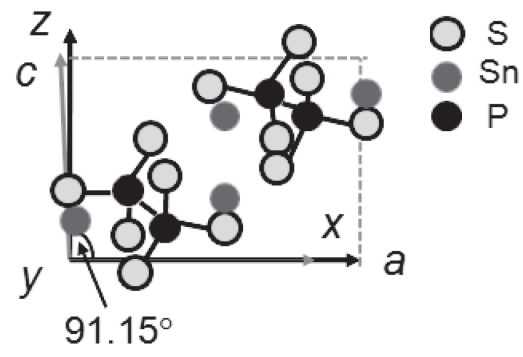

Fig. 10 Chemical structure of $\mathrm{Sn}_{2} \mathrm{P}_{2} \mathrm{~S}_{6}$ crystal.

うか，あるいは，如何にうまく手なづけるかが成否のカ ギを握る. これに対して, 最近, 半導体と強誘電体との 中間のバンドギャップを有するフェロエレクトロニック 半導体と呼ばれる新しいフォトリフラクティブ結晶が現 れた。この結晶は, 半導体と同等の高いキャリア移動度 と強誘電体と同等の大きな非線形性を示す. 代表的な フェロエレクトロニック結晶として $\mathrm{Sn}_{2} \mathrm{P}_{2} \mathrm{~S}_{6}$ 結晶があげ

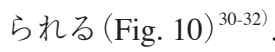

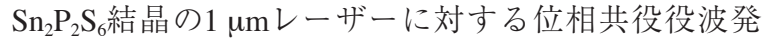
生の時間応答をFig. 11に示す. $\mathrm{Sn}_{2} \mathrm{P}_{2} \mathrm{~S}_{6}$ 結晶は, $\mathrm{BaTiO}_{3}$ 結 晶に比べ位相共役波の立ち上がり速度が2桁近く速く, $\mathrm{BaTiO}_{3}$ 結晶とほぼ同等の反射率 $(>40 \%)$ を示す。また, 相転移温度が室温 $(\sim 10$ 度 $)$ 近くにあり強冷却できない $\mathrm{BaTiO}_{3}$ 結晶に対して, $\mathrm{Sn}_{2} \mathrm{P}_{2} \mathrm{~S}_{6}$ 結晶には50度以下に相転 移温度がない。したがって，フォトリフラクティブ結晶 でしばしば起こる結晶温度上昇に伴う光損傷(デポーリ ング)を強冷却することで未然に回避できる。このよう に, $\mathrm{Sn}_{2} \mathrm{P}_{2} \mathrm{~S}_{6}$ 結晶は, 従来の位相共役レーザーシステム の性能は飛躍的に向上させる可能性がある.

この他, 超短パルスレーザーによるフォトリフラク ティブ効果の新展開としてFeドープ $\mathrm{LiNbO}_{3}$ における二 光子吸収を用いたスペクトルホログラム記録も注目に值 するが，詳細は西岡の解説記事に譲る.

\section{3. まとめ}

体積型ホログラフィック回折格子や偏光選択回折素子 やフェロエレクトロニック結晶など, 高機能回折光学素 子の進展は目覚ましい. 高出力レーザーのコヒーレント 結合, 軸対称偏光モード発生, 高出力位相共役レーザー など，これまで提案されていたものの実現性や実用性が 乏しかったアイデアが進化した回折光学素子を利用する ことで次々と具現化されていくその様はまさに“Dream comes true”である。

特に，1台のレーザーが出せるレーザー出力に限界が 見え始めているなか, 高効率なコヒーレント結合が実現 できれば，レーザーのパワーに事実上，上限がなくな る。今後の展開に目が離せない.

\section{参考文献}

1) O. M. Efimov, L. B. Glebov, L. N. Glebova, K. C. Richardson, and V. I. Smirnov: Appl. Opt. 38 (1999) 619.

2) O. M. Efimov, L. B. Glebov, and V. I. Smirnov: Opt. Lett. 25 1693-1695 (2000).

3) F. Pigeon, J. C. Pommier, S. Reynaud, O. Parriaux, M. A. Ahmed,

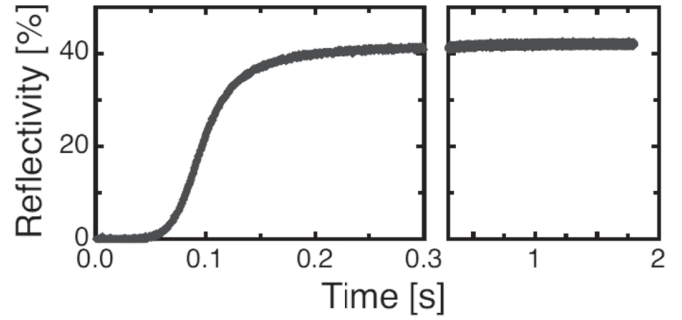

Fig. 11 Temporal behavior of $1 \mu \mathrm{m}$ phase conjugation in SPS crystal.

N. Landru, and J. P. Feve: Opt. Express 15 (2007) 2573.

4) R. Oron, S. Blit, N. Davidson, A A. Friesem, Z. Bomzon, and E. Hasman: Appl. Phys. Lett. 77 (2000) 3322.

5) P. Gunter and J.-P. Huignard ed.: Photorefractive Materials and Their Applications 3 (Springer-Verlag, Berlin, 2006).

6) A. Brignon and J.-P. Huignard ed.: Phase Conjugate Laser Optics, (Wiley, New Jersey, 2004).

7) A. Gourevitch, G. Venus, V. Smirnov, and L. Glebov: Opt. Lett. 32 (2007) 2611.

8) T. Chung, A. Rapaport, V. Smirnov, L. B. Glebov, M. C. Richardson, and M. Bass: Opt. Lett. 31 (2006) 229.

9) G. B. Venus, A. Sevian, V. I. Smirnov, and L. B. Glebov: Opt Lett. 31 (2006) 1453.

10) K.-H. Liao, M.-Y. Cheng, E. Flecher, V. I. Smirnov, L. B. Glebov, and A. Galvanauskas: Opt. Express 25 (2007) 4876.

11) Y. Sato, T. Taira, V. Smirnov, L. Glebova, and L. Glebov: Conference on Laser and Electro-Optics-European Quantum Electronics Conference (CLEO-QELS) 2009 (14-19 June 2009, Munich), CA9.4.

12) A. Gourevitch, G. Venus, V. Smirnov, and L. Glebov: Opt. Lett. 32 (2007) 2611.

13) A. Gourevitch, G. Venus, V. Smirnov, D. A. Hostutler, and L. Glebov: Opt. Lett. 33 (2008) 702.

14) A. Sevian, O. Andrusyak, I. Ciapurin, V. Smirnov, G. Venus, and L. Glebov: Opt. Lett. 33 (2008) 384.

15) S. Kawakami, T. Kawashima, and T. Sato: Appl. Phys. Lett. 74 (1999) 463.

16) J. Liu, K. Ueda, L. Zhong, M. Musha, A. Shirakawa, and T. Sato: Opt. Express 16 (2008) 10841.

17) T. Sato, K. Miura, N. Ishino, Y. Ohtera, T. Tamamura, and S. Kawakami: Opt. Quantum Electron. 34 (2002) 63.

18) Y. Kozawa, S. Sato, T. Sato, Y. Inoue, Y. Ohtera, and S. Kawakami: Appl. Phys. Express 1 (2008) 022008.

19) J. Hamazaki, A. Kawamoto, R. Morita, and T. Omatsu: Opt. Express 16 (2008) 16762

20) J. Feinberg: Opt. Lett. 7 (1982) 486.

21) S. MacCormack and J. Feinberg: Opt. Lett. 18 (1993) 211.

22) A. Brignon, J. P. Huignard, MH Garrett, and I. Mnushkina: Opt. Lett. 22 (1997) 442.

23) K. Tei, F. Matsuoka, M. Kato, Y. Maruyama, and T. Arisawa: Opt. Lett. 25 (2000) 481.

24) K. Nawata, Y. Ojima, M. Okida, T. Ogawa, and T. Omatsu: Opt. Express 14 (2006) 10657.

25) K. Nawata, M. Okida, K. Furuki, and T. Omatsu: Opt. Express 15 (2007) 9123

26) L. Lombard, A. Brignon, J.-P. Huignard, É. Lallier, G. LucasLeclin, P. Georges, G. Pauliat, and G. Roosen: Comptes rendusPhysique 7 (2006) 233.

27) A. Godard, G. Pauliat, G. Roosen, P. Graindorge, and P. Martin: Opt. Lett. 26 (2001) 1955

28) A. Godard, G. Pauliat, G. Roosen, and E. Ducloux: Appl. Opt. 43 (2004) 3543

29) T. Omatsu, A. Minassian, and M. J. Damzen: Jpn. J. Appl. Phys. 41 (2002) 2024

30) T. Bach, M. Jazbinsek, P. Gunter, A. Grabar, I. Stoika, and Y. Vysochanskii: Opt. Express 13 (2005) 9890.

31) M. Jazbinsek, D. Haertle, G. Montemezzani, P. Gunter, A. A. Grabar, I. M. Stoika, and Y. M. Vysochanskii: J. Opt. Soc. Am. B 22 (2005) 2459.

32) T. Bach, M. Jazbinsek, G. Montemezzani, P. Gunter, A. A. Grabar, I. Stoika, and Y. M. Vysochanskii: J. Opt. Soc. Am. B 24 (2007) 1535 . 